\section{Cross Breeding New Cultivars of Early-flowering Multiflora Chrysanthemum Based on Mathematical Analysis}

\author{
Mengmeng Zhang, He Huang, Qing Wang, and Silan Dai ${ }^{1}$ \\ Beijing Key Laboratory of Ornamental Plants Germplasm Innovation \& \\ Molecular Breeding, National Engineering Research Center for Floriculture, \\ Beijing Laboratory of Urban and Rural Ecological Environment, Key \\ Laboratory of Genetics and Breeding in Forest Trees and Ornamental \\ Plants of Ministry of Education, School of Landscape Architecture, Beijing \\ Forestry University, 35 East Qinghua Road, Beijing 100083, China
}

Additional index words. Chrysanthemum $\times$ morifolium, flowering time, crossbreeding, grading analysis, cluster analysis, comprehensive evaluation

\begin{abstract}
Conventional crossbreeding remains an effective technique for chrysanthemum (Chrysanthemum $\times$ morifolium Ramat.) breeding. However, there are always many problems when breeding chrysanthemum because of its complex genetic background, such as difficulty matching parents, selecting superior hybrid progenies, quantitatively describing certain target traits, and evaluating breeding results. A recent mathematical analysis method is an effective method for evaluating plant breeding progress. In this study, we used 505 multiflora chrysanthemum germplasm resources as test materials; we divided the flowering time into five groups using a grading analysis method, including extremely early group (genotypes that flowered when daylength was longer than $\mathbf{1 3 . 5}$ hours), early group (genotypes that flowered when daylength was 13.5-12.0 hours), medium group (genotypes that flowered when daylength was 12.0-11.0 hours), late group (genotypes that flowered when daylength was 11.0-10.0 hours), and extremely late group (genotypes that flowered when daylength was shorter than $\mathbf{1 0 . 0}$ hours). Moreover, the breeding objective was to breed early-flowering genotypes. Using 15 phenotypic characters as evaluation factors, 37 excellent genotypes, including four early-flowering genotypes, were screened out from the aforementioned resources according to an analytic hierarchy process (AHP) and weighting of the gray relational grade. We selected one early-flowering genotype and eight medium-flowering genotypes from these 37 genotypes and matched six hybridized combinations based on the genetic distance between genotypes calculated by the $Q$ cluster analysis method. We used a comprehensive evaluation method combining AHP and the gray relational analysis (GRA) method for the evaluation of 367 progenies. Moreover, we screened out 52 superior hybrids, including 36 early-flowering hybrids. The results of this study demonstrate that the mathematical analysis method is an immensely effective method to breed new cultivars of early-flowering multiflora chrysanthemum. This study also provides an effective method to define and improve the flowering time of other cultivated plants.
\end{abstract}

Because of its high ornamental value and wide range of applications, multiflora chrysanthemum (Chrysanthemum xmorifolium Ramat.) plays an important role in the global flower market (Anderson, 2006; Augustinova et al., 2016; Teixeira da Silva et al., 2013). However, most multiflora chrysanthemum

Received for publication 7 Dec. 2017. Accepted for publication 13 Feb. 2018.

This work was supported by the Introduction of International Advanced Forestry Science and Technology Research Projects (2013-4-28) and the Graduate Training and Development Program of Beijing Municipal Commission of Education (BLCXY201529).

We are sincerely grateful to the Beijing Dadongliu Nursery for providing plant materials.

${ }^{1}$ Corresponding author. E-mail: silandai@sina. com. cultivars are short-day plants, which initiate flowering when the daylength is shorter than 12 h (Cockshull, 1985). Thus, they usually flower from late October to November. To meet market demands, growers have been using techniques to regulate (such as shading in summer) and advance flowering (Ochiai et al., 2015). These techniques are rather costly and laborious, causing the ornamental quality to decline. Therefore, advancing flowering is an important breeding objective for multiflora chrysanthemum.

Flowering time, an important adaptive trait that strongly influences planting area and productivity and the market price of cultivated plants, is affected by both endogenous and environmental factors. An accurate definition of flowering time will be vital for breeding research and the practical production of ornamental plants. The number of days between the transplanting date and the initial flowering date has been recorded as initial flowering time in previous studies (Zhang et al., 2011, 2013). However, to date, flowering time has only been qualitatively described and not quantitatively analyzed. In The guidelines for the conduct of tests for distinctness, homogeneity and stabilityChrysanthemum, published and implemented by The International Union for the Protection of New Varieties of Plants (UPOV), flowering time is divided into three groups, including early group, medium group, and late group (UPOV, 2010). However, because of the lack of a numerical index to define flowering time groups, the evaluation criteria are always different among breeding programs. The establishment of a numerical grading index of flowering time is the basis for the normalized and standard description of multiflora chrysanthemum germplasm resources.

Chrysanthemum cultivars are genetically highly heterozygous, so conventional crossbreeding between parental cultivars with contrasting target traits is still the most effective way to breed new cultivars (Teixeira da Silva et al., 2013). The key to success is parent-pair selection; therefore, the genetic difference between parents is an important factor. Parental genetic difference and hybrid performance are positively related (Ajmone Marsan et al., 1998; Hung et al., 2012). Compared with molecular markers and other methods, morphological markers are easier to observe and obtain. In chrysanthemum, previous studies that used the cluster analysis method based on morphological markers were considerably restricted to studying cultivar classification (Zhang et al., 2014a) rather than evaluating the genetic difference between parents (Su et al., 2017). Moreover, breeding new cultivars is a sophisticated technique. Intraspecific and interspecific hybridization has been used to improve the plant type (Anderson and Ascher, 2016; Chen et al., 1995), stress resistance (Cheng et al., 2011), flower color (Anderson et al., 2014), and even flowering time of chrysanthemum. Although a series of new cultivars with different flowering times have been obtained (Anderson and Ascher, 2016), the number of early-flowering multiflora chrysanthemum cultivars is still limited (Lim et al., 2012, 2014). In particular, other ornamental traits of some cultivars tend to perform poorly during introduction and cultivation. Further studies are needed to breed superior early-flowering multiflora chrysanthemums that are suitable for different geographical cultivation conditions.

Comprehensive evaluation of hybrids is an important part of breeding. The primary breeding objective should be considered when selecting superior hybrids of ornamental plants, and conversely, comprehensive traits including flower-related traits, leaf-related traits, vegetative-related traits, and stress resistance should also be considered. It is imperative to establish a scientific, reasonable, and feasible comprehensive evaluation system. The GRA method is a comprehensive 
evaluation approach for the gray system. It is characterized by less data and can avoid inconsistency between results of quantitative and qualitative analyses (Deng, 1989). This method has been widely used in various fields of science, including the evaluation of new crop cultivars. However, it has a strong subjectivity in the determination of the weight of traits. AHP is a systematic and hierarchical analysis method for combining qualitative and quantitative analysis methods and can decompose complex problems into multiple layers and multiple factors (Saaty, 1990). It can easily calculate the weight of each trait but cannot make full use of the original information. A comprehensive evaluation system combining the AHP and GRA methods would be practical and comprehensive, allowing these methods to complement each other. This system has been widely used in industry, environment, architecture, and many other fields (Huang and Wang, 2014; Liang et al., 2015; Xu et al., 2011). It also has been used to evaluate a variety of resources and select new cultivars in many crops, and results have shown that it is an effective method for the comprehensive evaluation of germplasm resources (Ma et al., 2012; Xiong et al., 2015). This comprehensive evaluation system has less application in chrysanthemum breeding. Considering plant type as the main breeding objective, Wang et al. (2012) first used this method and selected new cultivars with excellent comprehensive characters quickly and effectively. Different main breeding objectives and a different judgment matrix constructed in AHP result in different weights of each index. A study using this method to select early-flowering multiflora chrysanthemum has not been reported.

In this study, we used several mathematical analysis methods to establish the numerical grading index of flowering time, comprehensively evaluate germplasm resources, select and match crossing parents, and screen out superior hybrids. The objectives of this study were to provide an effective method for multiflora chrysanthemum breeding by conventional crossbreeding and to provide a reference method for breeding programs of other ornamental plants.

\section{Materials and Methods}

Plant materials. A total of 505 multiflora chrysanthemum germplasm resources were used in this study and were maintained at the chrysanthemum germplasm nursery, Beijing Forestry University, China (Supplemental Table 1). These included eight cultivars of Timeline introduced from the Netherlands, $430 \mathrm{~F}_{1}$ progenies obtained from natural crossing between Timeline and chinese chrysanthemum, four cultivars of the Bran Multiflora line introduced from Germany (Brandkamp Company), and $63 \mathrm{~F}_{1}$ progenies obtained from artificial crossing between Bran Multiflora and the other germplasms.

Sexual hybridization and cultivation. An artificial hybridization test was conducted during Fall 2013. Before the disc flowers of female parents lost powder, the disc flowers were removed for emasculation, and the ray flowers were docked to expose the stigma; then, the capitulum was covered with a paper bag. Pollen collected from freshly opened flowers of male parents was transferred to "Y" type stigma of the emasculated flower of female parents with a brush, and the pollinated flowers were re-enclosed in a paper bag. Pollination was carried out once a day, and each capitulum was pollinated three to five times continuously for a week. After $\approx 60 \mathrm{~d}$ of natural growth, the capitula were collected, and the seeds were screened out; then, they were kept in a dry and ventilated place.

All experiments were completed in solar greenhouses of the chrysanthemum breeding nursery of Beijing Forestry University. In Feb. 2014, seeds were sown in 128-cell trays. After $\approx 30 \mathrm{~d}$, the surviving seedlings, which had been pinched, were transplanted to 81cell trays. Parents and $\mathrm{F}_{1}$ progenies were propagated by cutting in April, and rooted cuttings were transplanted to pots on 6 June. The size of the pots was $19 \mathrm{~cm} \times 17 \mathrm{~cm}$ and the plant spacing was $35 \mathrm{~cm} \times 35 \mathrm{~cm}$ in the planting bed. Standard commercial practices were used to manage the plants, which flowered naturally in the fall. In 2015 and 2016, the parents and $F_{1}$ progenies were propagated by cuttings, and field management and planting time were the same as those in 2014.

Data collection. Continuous tests for 15 phenotypic traits (Table 1) of germplasm resources (2012-13) and $F_{1}$ progenies (2014-16) were performed. At least three randomly selected plants per genotype were measured, and average values were used in statistical analysis. According to Zhang et al. (2011), the initial flowering date was defined as when $\approx 50 \%$ of the total flower buds were half-opened and fully pigmented, and the wilting flower date was defined as when $\approx 10 \%$ of the total flowers appeared wilted. The color of the inner side of the ray floret was measured according to Hong et al. (2012).

Grading analysis method of flowering time. From 2012 to 2016, the daylength of key time nodes in the Beijing area was almost the same (Supplemental Table 2). It indicated that the daylengths on the same date in different years were almost the same. Most chrysanthemum cultivars maintain vegetative growth when the daylength is longer than $13.5 \mathrm{~h}$ and initiate flowering when daylength is shorter than $12.0 \mathrm{~h}$ (Cockshull, 1985). In this study, we used 13.5, 12.0, 11.0, and $10.0 \mathrm{~h}$ as points of division to perform the grading analysis of flowering time.

Comprehensive evaluation method of multiflora chrysanthemum germplasm resources and $F_{1}$ progenies. A comprehensive evaluation method combining AHP and GRA was used to evaluate germplasm and screen out superior early-flowering hybrids from $F_{1}$ progenies.

A multihierarchy analytic model was constructed based on the relationship between
15 traits (Table 2). Target layer (A): superior early-flowering multiflora chrysanthemum genotypes; constrained layer (C): three main factors that influence the ornamental value of multiflora chrysanthemum, including flowering time-related traits, flower head-related traits, and vegetative-related traits; and index layer $(\mathrm{P})$ : including 15 specific evaluation indexes.

The judgment matrix was structured, and the greatest characteristic root and characteristic vector were calculated (Supplemental Tables 3-6). The characteristic vector of each judgment matrix was the weight of the lower index relative to that of the upper index.

The "reference cultivar" $\mathrm{X}_{0}$ was constructed based on the breeding objective and the actual observed value. Then, taking $\mathrm{X}_{0}$ as the reference sequence and observed genotypes as the compare sequence, gray relational coefficients were calculated. Thus, the weight value (represented by $r$ ) of each genotype was calculated by including the weight value of 15 traits that were calculated by AHP in the equation (Wang et al., 2012).

Cluster analysis method. Using PASW Statistics (version 20.0) software, a depiction of $\mathrm{R}$ cluster analysis of the selected 15 phenotypic traits and Q cluster analysis of the superior genotypes was constructed using a between-groups linkage method based on squared Euclidean distance.

\section{Results}

Grading analysis of flowering time of multiflora chrysanthemum germplasm resources. Given that most chrysanthemum cultivars remain in vegetative growth when the daylength is longer than $13.5 \mathrm{~h}$ and start reproductive growth when the daylength is shorter than $12.0 \mathrm{~h}$ (Cockshull, 1985), the daylength was classified as long day (when daylength was longer than $13.5 \mathrm{~h}$ ), short day (when daylength was 13.5-10.0 h), and extremely short day (when daylength was shorter than $10.0 \mathrm{~h}$ ). Then, the flowering time of the multiflora chrysanthemum was classified into five continuously distributed grading ranges: extremely early group (genotypes that flowered when daylength was longer than $13.5 \mathrm{~h}$ ), early group (genotypes that flowered when daylength was 13.5-12.0 h), medium group (genotypes that flowered when daylength was 12.0-11.0 h), late group (genotypes that flowered when daylength was $11.0-10.0 \mathrm{~h}$ ), and extremely late group (genotypes that flowered when daylength was shorter than $10.0 \mathrm{~h}$ ). Moreover, these five flowering time groups corresponded to the flowering time and flowering date (Table 3).

Comprehensive evaluation of breeding value of multiflora chrysanthemum germplasm resources. The comprehensive evaluation method combining AHP and GRA has been used for the evaluation of germplasm resources (Table 4). The weight value of the index layer (P) relative to the target layer (A) was calculated based on Supplemental Tables 3-6. The results showed that, in the three constrained layers, the weight value of flowering 
Table 1. Fifteen phenotypic traits measured in this study, their measuring methods, and evaluation for qualitative traits.

\begin{tabular}{|c|c|c|}
\hline Code & Trait & Measuring method and evaluation for qualitative traits \\
\hline$\overline{\mathrm{P} 1}$ & Flowering time & $\begin{array}{l}\text { Number of days between transplanting time and } \\
\text { initial flowering time (days) }\end{array}$ \\
\hline $\mathrm{P} 2$ & Flowering duration & $\begin{array}{l}\text { Number of days between initial flowering time } \\
\text { and flower wilting time (days) }\end{array}$ \\
\hline P3 & Flower head diameter & $\begin{array}{l}\text { Measure diameter at widest point of terminal } \\
\text { flower head }(\mathrm{cm})\end{array}$ \\
\hline P4 & Peduncle length & $\begin{array}{l}\text { Measure length from the bottom of the phyllary to } \\
\text { the first true leaf }\end{array}$ \\
\hline P5 & Flower head type & $\begin{array}{l}\text { Visual assessment; single (1), semidouble (2), } \\
\quad \text { daisy-eyed double (3), double (4), without ray florets (5) }\end{array}$ \\
\hline P6 & $\begin{array}{l}\text { Predominant type of ray } \\
\text { floret }\end{array}$ & $\begin{array}{l}\text { Visual assessment; flat type (1), spoon type (2), } \\
\text { tubular type (3) }\end{array}$ \\
\hline P7 & $\begin{array}{l}\text { Number of colors of ray } \\
\text { floret inner side }\end{array}$ & Visual assessment; one (1), two (2), more than two (3) \\
\hline P8 & $\begin{array}{l}\text { Main color of ray floret } \\
\text { inner side }\end{array}$ & $\begin{array}{l}\text { Brown group (1), orange group (2), pink group (3), } \\
\text { purple group (4), red group (5), white group (6), } \\
\text { yellow group (7), yellow-green group (8), } \\
\text { dark red group (9) }\end{array}$ \\
\hline P9 & $\begin{array}{l}\text { Second color of ray } \\
\text { floret inner side }\end{array}$ & The same as main color of inner side of ray floret \\
\hline P10 & Plant height & $\begin{array}{l}\text { Measure height from the bottom of the stem to the top } \\
\text { of the plant }(\mathrm{cm})\end{array}$ \\
\hline P11 & Crown diameter & Measure diameter at the widest point from the top face $(\mathrm{cm})$ \\
\hline P12 & Leaf length & Measure length of leaf on the middle third of the stem \\
\hline P13 & Leaf width & Measure width of leaf on the middle third of the stem \\
\hline P14 & Branching density & Visual assessment; dense (1), medium (2), sparse (3) \\
\hline P15 & Flower density & Visual assessment; dense (1), medium (2), sparse (3) \\
\hline
\end{tabular}

Table 2. The layered structure model of 15 evaluation indexes in multiflora chrysanthemum.

\begin{tabular}{lll}
\hline Target layer (A) & Constrained layer (C) & \multicolumn{1}{c}{ Index layer (P) } \\
$\begin{array}{l}\text { Superior early-flowering multiflora } \\
\text { chrysanthemum genotypes }\end{array}$ & $\begin{array}{c}\text { C1 flowering time-related } \\
\text { traits } \\
\text { C2 flower head-related } \\
\text { traits } \\
\text { C3 vegetative-related } \\
\text { traits }\end{array}$ & P1, P2 \\
\hline
\end{tabular}

time-related traits was the largest $(0.750)$, followed by that of flower head-related traits (0.171), and the smallest was that of vegetative-related traits $(0.078)$. In the 15 selected indexes, the weight value of the flowering time was the largest $(0.657)$, followed by that of the flowering duration (0.0938). The order of the other traits can be seen in Table 4.

Based on the grading index of the flowering time in Table 3, we evaluated the flowering time of 505 germplasm resources. The results showed that there were no extremely early-flowering genotypes and only nine early-flowering genotypes, which accounted for $1.8 \%$ of the germplasm. There were 41 medium-flowering genotypes, which accounted for $8.1 \%$. The number of late-flowering genotypes was the greatest, at 375 , and accounted for $74.3 \%$. Moreover, there were 80 extremely late-flowering genotypes, which accounted for $15.8 \%$ (Table 5). Therefore, the flowering time of multiflora chrysanthemum germplasm resources was late, and the number of earlyflowering genotypes was small. Based on these results, breeding early-flowering cultivar was taken as a breeding objective in this study.

Subsequently, these germplasm resources were ordered according to the weight value (represented by $r$ ) and were divided into three grades (Table 5). There were 37 genotypes in grade one $(r \geq 0.826)$. Except for four genotypes that belonged to the early group, there were 30 medium-flowering genotypes and three late-flowering genotypes. However, the flowering duration of these genotypes was longer, and the comprehensive characters were excellent. They are important germplasms for improving flowering time in the future. There were 216 genotypes in grade two $(0.771 \leq r<0.826)$. Most genotypes were late flowering with a shorter flowering duration. Therefore, these genotypes had a certain defect. There were 252 genotypes in grade three $(r<0.771)$. Among these, most were late flowering with poor comprehensive characters. These results indicated that a few germplasm resources could conform to the breeding objective.

Sexual hybridization to create new early-flowering germplasms of multiflora chrysanthemum. The result of $\mathrm{R}$ cluster analysis of 15 selected traits showed that only the characters leaf length and leaf width were correlated, whereas the other 13 traits were independent, indicating the rationality of selection of these traits (as shown in Fig. 1A). The result of $\mathrm{Q}$ cluster analysis between 37 superior germplasm resources, which belonged to grade one in Table 5 based on Euclidean distance, is shown in Fig. 1B. The horizontal axis represents the cluster level of each group and the vertical axis represents 37 genotypes (numbered from 1 to 37) ranking from the biggest to the smallest according to the weight value.

One early-flowering (A20) and eight medium-flowering genotypes (as shown in Supplemental Fig. 1) were selected as crossing parents from 37 superior genotypes, and six hybridized combinations were matched using them (Table 6) according to the following principles: genetic distance was farther between crossing parents, sources of crossing parents were different, flowering times of the crossing parents were similar, female parent was double-flowered, male parent had a large number of pollen grains, colors of crossing parents were different, and comprehensive characters were excellent.

A total of 105 flower heads were pollinated and 961 seeds were collected in Fall 2013. The mean number of seed per flower head of combination A was 18.8, which was the highest; those of combinations $\mathrm{B}$ and $\mathrm{C}$ were 8.8 and 12.1, respectively; and those of combinations D, E and F were lower. These seeds were seeded in Spring 2014 and 406 seeds germinated. Low seed germination rates were observed for the six hybridized combinations and $367 \mathrm{~F}_{1}$ progenies flowered in Fall 2014. The seedling rate of combination A $(84.0 \%)$ was lower than that of the other five combinations (Table 7).

Based on the grading index of flowering time in Table 3 , we evaluated the flowering time of $367 \mathrm{~F}_{1}$ progenies (Table 8). There were two extremely early-flowering hybrids (accounted for $0.5 \%$, Supplemental Table 7) and 71 early-flowering hybrids (accounted for $19.4 \%$ ). Medium- and late-flowering hybrids accounted for $53.4 \%$ and $26.7 \%$, respectively. Moreover, there were no extremely late-flowering hybrids. Compared with the germplasm resources, we obtained extremely early-flowering genotypes and the number of early-flowering genotypes was markedly increased.

Based on the weight value of every index in Table 4, the weight value (represented by $r$ ) of the $F_{1}$ progenies were calculated. Moreover, $367 \mathrm{~F}_{1}$ progenies were divided into three grades (Table 8). There were 52 hybrids in grade one $(r \geq 0.851)$. Among them, 36 hybrids belonged to the early-flowering group. These 36 hybrids with good comprehensive characters (red color, long flowering duration, double flowered and big crown diameter) accorded with the demands of the market and could be potential new cultivars. There were 147 hybrids in grade two $(0.822 \leq$ $r<0.851)$. Most of them were medium flowering and a few were early or late flowering. The main flower color was red, pink, or purple and most hybrids had specific defects. There were 168 hybrids in grade three $(r<$ 0.822). Among these, most were medium flowering with poor comprehensive characters. Finally, 36 early-flowering hybrids (Supplemental Table 8) with good comprehensive characters were screened out. A comprehensive analysis of the aforementioned data showed that the expected breeding objective was achieved. 
Table 3. Grading criteria for flowering time of multiflora chrysanthemum.

\begin{tabular}{llllll}
\hline Grade & \multicolumn{1}{c}{1} & \multicolumn{1}{c}{2} & \multicolumn{1}{c}{4} & \multicolumn{1}{c}{5} \\
\hline Daylength $\left(\mathrm{h} \cdot \mathrm{d}^{-1}\right)$ & $\geq 13.5$ & $13.5-12.0$ & $12.0-11.0$ & $11.0-10.0$ & $<10.0$ \\
Daylength group & Long day & Short day & Short day & Short day & Extremely short day \\
Flowering time group & Extremely early group & Early group & Medium group & Late group & Extremely late group \\
Grading range of flowering date & Before Aug. 23 & Aug. 24 to Sept. 26 & Sept. 27 to Oct. 20 & Oct. 21 to Nov. 15 & After Nov. 15 \\
Grading range of flowering time (d) & $\leq 75$ & $76-110$ & $111-134$ & $135-160$ & $>160$ \\
\hline
\end{tabular}

Table 4. Weight value of the evaluation indexes.

\begin{tabular}{|c|c|c|c|c|c|}
\hline \multicolumn{2}{|c|}{ Layer $\mathrm{C}$ contributes to layer $\mathrm{A}$} & Index layer $\mathrm{P}$ & Layer $\mathrm{P}$ contributes to layer $\mathrm{C}$ & Layer $\mathrm{P}$ contributes to layer A & Order \\
\hline$\overline{\mathrm{C} 1}$ & 0.750 & P1 & 0.875 & 0.657 & 1 \\
\hline \multirow[t]{5}{*}{$\mathrm{C} 2$} & 0.171 & P3 & 0.110 & 0.0189 & 7 \\
\hline & & P4 & 0.0654 & 0.0112 & 9 \\
\hline & & P6 & 0.0430 & 0.0074 & 11 \\
\hline & & P7 & 0.0627 & 0.0107 & 10 \\
\hline & & P8 & 0.421 & 0.0722 & 3 \\
\hline \multirow[t]{5}{*}{ C3 } & 0.078 & P11 & 0.0694 & 0.0054 & 13 \\
\hline & & P12 & 0.0414 & 0.0032 & 14 \\
\hline & & P13 & 0.0269 & 0.0021 & 15 \\
\hline & & P14 & 0.414 & 0.0324 & 5 \\
\hline & & P15 & 0.287 & 0.0224 & 6 \\
\hline
\end{tabular}

Table 5. Results of comprehensive evaluation and grade division in multiflora chrysanthemum germplasm.

\begin{tabular}{|c|c|c|c|c|c|c|c|c|}
\hline Grade & Wt value $(r)$ & $\begin{array}{c}\text { No. } \\
\text { genotypes }\end{array}$ & $\begin{array}{l}\text { Proportion } \\
(\%)\end{array}$ & $\begin{array}{l}\text { No. extremely } \\
\text { early-flowering } \\
\text { genotypes }\end{array}$ & $\begin{array}{l}\text { No. early-flowering } \\
\text { genotypes }\end{array}$ & $\begin{array}{l}\text { No. medium-flowering } \\
\text { genotypes }\end{array}$ & $\begin{array}{l}\text { No. late-flowering } \\
\text { genotypes }\end{array}$ & $\begin{array}{l}\text { No. extremely } \\
\text { late-flowering } \\
\text { genotypes }\end{array}$ \\
\hline 1 & $r \geq 0.826$ & 37 & 7.33 & 0 & 4 & 30 & 3 & 0 \\
\hline 2 & $\begin{array}{l}0.771 \leq r< \\
0.826\end{array}$ & 216 & 42.8 & 0 & 2 & 7 & 176 & 31 \\
\hline 3 & $r<0.771$ & 252 & 49.9 & 0 & 3 & 4 & 196 & 49 \\
\hline Total & $\begin{array}{l}\text { Number of } \\
\text { genotypes }\end{array}$ & 505 & & 0 & 9 & 41 & 375 & 80 \\
\hline
\end{tabular}
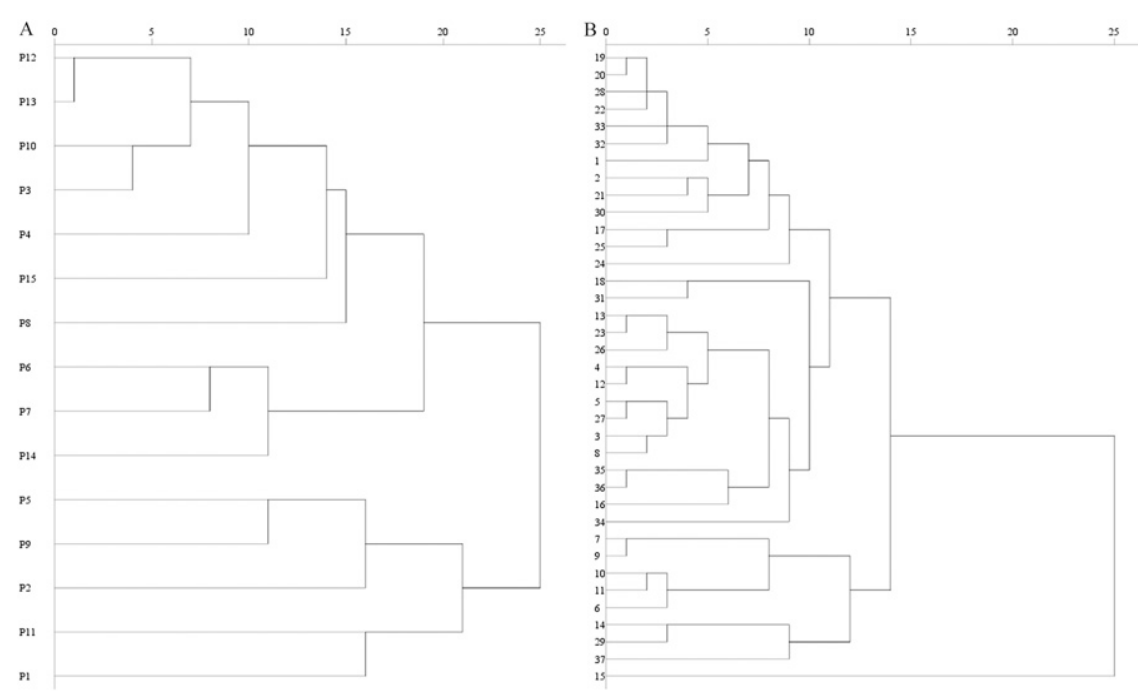

Fig. 1. Depiction of cluster analysis of 37 superior genotypes screened from germplasm resources: (A) R cluster analysis diagram of 15 characters; (B) Q cluster analysis diagram of 37 genotypes.

\section{Discussion}

Grading analysis of flowering time. The establishment of a scientific and rigorous numerical grading index is the basis for further research of the target trait. Luo et al.
(2016) have established a grading index of 19 quantitative traits of Chinese traditional chrysanthemum using the probability grading method. However, the flowering time was not analyzed, and the method did not apply to the grading analysis of quantitative trait that skew distribution. According to Zhang et al. (2014b), 82 ornamental crabapple cultivars were divided into five major flowering groups with $5 \mathrm{~d}$ ( $5 \mathrm{~d}$ is a "Hou" in Chinese) as the level differential. There were only $22 \mathrm{~d}$ between the earliest and latest flowering cultivars of ornamental crabapple but there were $61 \mathrm{~d}$ of multiflora chrysanthemum in our study. Therefore, this method was also not appropriate for our study. In a chrysanthemum DUS (distinctness, uniformity, and stability) test (UPOV, 2010), the flowering time was divided into three groups, including the early group, medium group, and late group. However, chrysanthemum lacks a numerical index to define the flowering time group in this grading method. Most chrysanthemum cultivars show vegetative growth when the daylength is longer than $13.5 \mathrm{~h}$ and start reproductive growth when the daylength is shorter than $12.0 \mathrm{~h}$ (Cockshull, 1985). In this study, considering the natural blooming time of multiflora chrysanthemum in the Beijing area as an example, we have established a grading index of flowering time based on the aforementioned character of multiflora chrysanthemum. The flowering time of multiflora chrysanthemum was divided into five groups: extremely early group (genotypes that flowered when daylength was 
Table 6. Description list of combinations and the main ornamental characters of parents in sexual hybridization.

\begin{tabular}{|c|c|c|c|c|c|c|c|}
\hline $\begin{array}{l}\text { Code of } \\
\text { combination }\end{array}$ & $\begin{array}{l}\text { Name of } \\
\text { parents }\end{array}$ & $\begin{array}{l}\text { Type of } \\
\text { parents }\end{array}$ & $\begin{array}{l}\text { Ordered by } \\
\text { wt value }\end{array}$ & Source & $\begin{array}{c}\text { Flowering } \\
\text { time (d) }\end{array}$ & $\begin{array}{l}\text { Main color } \\
\text { of inner side } \\
\text { of ray floret }\end{array}$ & Flower head type \\
\hline \multirow[t]{2}{*}{$\mathrm{A}$} & Brancandy & Female parent & 18 & Germany Brandkamp Company & 125 & Pink group & Daisy-eyed double \\
\hline & 317 & Male parent & 15 & Breeding performed ourselves & 133 & Pink group & Semidouble \\
\hline \multirow[t]{2}{*}{ B } & Brankiss & Female parent & 17 & Germany Brandkamp Company & 122 & Pink group & Daisy-eyed double \\
\hline & A49 & Male parent & 11 & Breeding performed ourselves & 118 & Red group & Single \\
\hline \multirow[t]{2}{*}{$\mathrm{C}$} & $\mathrm{A} 20$ & Female parent & 1 & Breeding performed ourselves & 106 & Pink group & Daisy-eyed double \\
\hline & A42 & Male parent & 24 & Breeding performed ourselves & 114 & Red group & Semidouble \\
\hline \multirow[t]{2}{*}{$\mathrm{D}$} & Brankiss & Female parent & 17 & Germany Brandkamp Company & 122 & Pink group & Daisy-eyed double \\
\hline & A7 & Male parent & 4 & Breeding performed ourselves & 116 & Yellow group & Semidouble \\
\hline \multirow[t]{2}{*}{$\mathrm{E}$} & Brancandy & Female parent & 18 & Germany Brandkamp Company & 125 & Pink group & Daisy-eyed double \\
\hline & A38 & Male parent & 31 & Breeding performed ourselves & 111 & Red group & Semidouble \\
\hline \multirow[t]{2}{*}{$\mathrm{F}$} & Brankiss & Female parent & 17 & Germany Brandkamp Company & 122 & Pink group & Daisy-eyed double \\
\hline & $\mathrm{Ca} * 388-45$ & Male parent & 27 & Breeding performed ourselves & 111 & Orange group & Single \\
\hline
\end{tabular}

Table 7. Statistical analysis of the results of sexual hybridization in multiflora chrysanthemum.

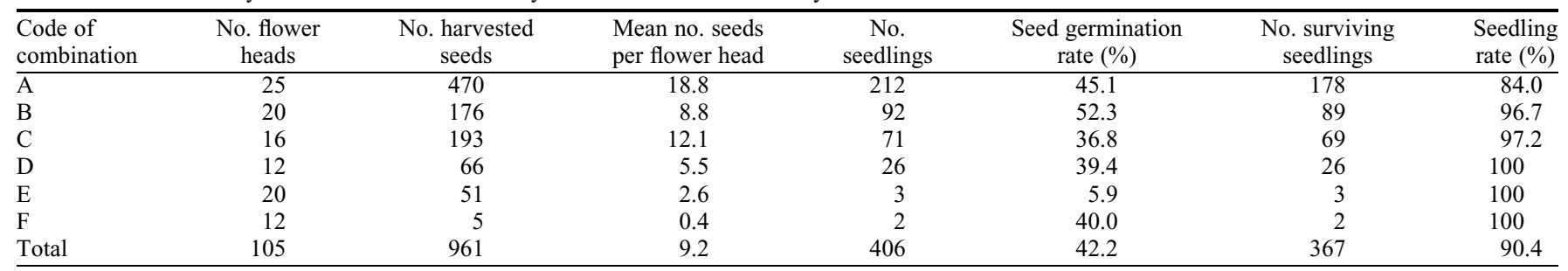

Table 8. Results of the comprehensive evaluation and grade division in $\mathrm{F}_{1}$ progenies of multiflora chrysanthemum.

\begin{tabular}{|c|c|c|c|c|c|c|c|c|}
\hline Grade & Wt value $(r)$ & $\begin{array}{c}\text { No. } \\
\text { genotypes }\end{array}$ & $\begin{array}{l}\text { Proportion } \\
\quad(\%)\end{array}$ & $\begin{array}{l}\text { No. extremely } \\
\text { early-flowering } \\
\text { genotypes }\end{array}$ & $\begin{array}{l}\text { No. early-flowering } \\
\text { genotypes }\end{array}$ & $\begin{array}{l}\text { No. medium-flowering } \\
\text { genotypes }\end{array}$ & $\begin{array}{l}\text { No. late-flowering } \\
\text { genotypes }\end{array}$ & $\begin{array}{c}\text { No. extremely } \\
\text { late-flowering } \\
\text { genotypes }\end{array}$ \\
\hline 1 & $r \geq 0.851$ & 52 & 14.2 & 0 & 36 & 11 & 5 & 0 \\
\hline 2 & $\begin{array}{l}0.822 \leq r< \\
0.851\end{array}$ & 147 & 40.1 & 1 & 13 & 76 & 57 & 0 \\
\hline 3 & $r<0.822$ & 168 & 45.8 & 1 & 22 & 109 & 36 & 0 \\
\hline Total & $\begin{array}{l}\text { Number of } \\
\text { genotypes }\end{array}$ & 367 & & 2 & 71 & 196 & 98 & 0 \\
\hline
\end{tabular}

longer than $13.5 \mathrm{~h}$ ), early group (genotypes that flowered when daylength was 13.5-12.0 h), medium group (genotypes that flowered when daylength was 12.0-11.0 h), late group (genotypes that flowered when daylength was $11.0-10.0 \mathrm{~h}$ ), and extremely late group (genotypes that flowered when daylength was shorter than $10.0 \mathrm{~h}$ ). The flowering time of multiflora chrysanthemum was further refined, and each group corresponded to the flowering time and flowering date. We quantitatively described our breeding objective, and it not only was convenient for evaluating the breeding results but also provided references for defining the flowering time of multiflora chrysanthemum cultivated in different areas. These results were supplemented the chrysanthemum DUS test and established a foundation to perform a normalized and standard description of chrysanthemum flowering time. Moreover, it provided a method for grading analysis of the other quantitative traits.

Breeding results of early-flowering breeding of multiflora chrysanthemum. The investigation of multiflora chrysanthemum germplasm resources in the Beijing area showed that there were few early-flowering genotypes. In the 505 germplasm resources, there were only nine early-flowering genotypes (accounted for $1.8 \%$ ). Only four earlyflowering genotypes with good comprehensive characters were selected out through a comprehensive evaluation. One early-flowering and eight medium-flowering genotypes were used as crossing parents to obtain $367 \mathrm{~F}_{1}$ progenies, including 71 early-flowering hybrids (accounted for 19.4\%) and two extremely early-flowering hybrids (Supplemental Table 7). These two extremely early-flowering hybrids can flower under long day conditions, so they may be day-neutral genotypes, but further study is needed. Thirty-six earlyflowering hybrids with excellent comprehensive characters were selected through comprehensive evaluation (Supplemental Table 8) and could be developed into new cultivars. Thus, the breeding objective is complete and traditional crossing breeding is an effective method for improving the flowering time of multiflora chrysanthemum.

In this study, relatively few extremely early-flowering genotypes were obtained. Breeding to improve the flowering time of multiflora chrysanthemum needs further improvements and increased efforts. Considering combinations $\mathrm{A}, \mathrm{B}$, and $\mathrm{C}$, the flowering time of most $F_{1}$ progenies was the same as that of their parents. In addition, some variations flowered earlier than their parents. Among these three combinations, the number of early-flowering $F_{1}$ progenies in combina- tion $\mathrm{C}$ was the most. Therefore, the breeding result of combination $\mathrm{C}$ was the best. Among the parents of these three combinations, only the female parent of combination $\mathrm{C}$ belonged to the early group; all others belonged to the medium group. This result showed that it was easier to get early-flowering progenies using parents that flowered earlier. The results were similar to those obtained by other researchers (Fukai et al., 2000). Therefore, these two extremely early-flowering and 36 earlyflowering hybrids were elite germplasms for breeding extremely early-flowering multiflora chrysanthemum.

Application of mathematical analysis method in ornamental plant breeding. Proper parent-pair selection is a prerequisite to achieving the breeding objective. Because of its complex genetic background, the parent-pair selection is difficult for chrysanthemum, and the traditional method of selecting and matching parents is grueling and time-consuming (Bestfleisch et al., 2014; Zeng et al., 2014). The correlation between parental genetic distance and hybrid performance using morphological and molecular markers, respectively, was measured in chrysanthemum (Su et al., 2017). However, only waterlogging tolerance-related characters were discussed. In this study, the genetic distances between 37 superior genotypes 
were measured by cluster analysis of 15 morphological markers. Moreover, six hybridized combinations were matched based on the cluster results. The method based on genetic distance to select and match parents has been used in the breeding of Liriodendron (Yao et al., 2016), chinese cabbage (Kawamura et al., 2016), and other crops. However, there are few studies using this method in chrysanthemum. Using this method, we found that the flowering time of $F_{1}$ was promoted. Therefore, the parent-pair selection method that we used was effective.

The hybrid progenies of chrysanthemum are widely separated, so it is a challenge for chrysanthemum breeders to evaluate breeding results accurately. The complexity of ornamental plant breeding lies not only in the need to achieve the main breeding objective but also to consider comprehensive characters of new cultivars. This objective needs to evaluate hybrid progenies comprehensively. The GRA method is a comprehensive evaluation approach for the gray system. However, it has strong subjectivity in the determination of the weight of traits. Using AHP, the weight of every index relative to comprehensive characters can be calculated by structuring the judgment matrix. Moreover, it is more objective and reasonable to determine the weight. A comprehensive evaluation system combining the AHP and GRA methods can allow these methods to complement each other. This combined method has been widely used in many fields (Huang and Wang, 2014; Liang et al., 2015; Xu et al., 2011). It also has been used in the comprehensive evaluation of winter jujube (Ma et al., 2012), tulip (Xiong et al., 2015), and other crops. If the main breeding objectives are different and the judgment matrix constructed in AHP is different, the weights of each index are different. Considering the plant type as the main breeding objective, Wang et al. (2012) first used this method to perform a comprehensive evaluation of multiflora chrysanthemum and selected 43 genotypes with excellent comprehensive characters. In this study, we used flowering time as the main breeding objective by redefining flowering time and selected 36 early-flowering hybrids with excellent comprehensive characters using this method. The results showed that this is an effective and comprehensive evaluation method.

\section{Literature Cited}

Ajmone Marsan, P., P. Castiglioni, F. Fusari, M. Kuiper, and M. Motto. 1998. Genetic diversity and its relationship to hybrid performance in maize as revealed by RFLP and AFLP markers. Theor. Appl. Genet. 96(2):219-227.

Anderson, N.O. 2006. Chrysanthemum. Dendranthema xgrandiflora Tzvelv, p. 389-437. In: N.O. Anderson (ed.). Flower breeding and genetics: Issues, challenges, and opportunities for the 21st century. Springer, Dordrecht, The Netherlands.

Anderson, N.O. and P. Ascher. 2016. Chrysanthemum xgrandiflorum MN Sel'n. 90-275-27 groundcover garden chrysanthemum. HortScience 51:451-455.
Anderson, N.O., E. Gesick, V. Fritz, C. Rohwer, S. Yao, P. Johnson, S. Poppe, B.E. Liedl, L. Klossner, N. Eash, and J. Reith-Rozelle. 2014. Mammoth $^{\text {TM }}$ series garden chrysanthemum 'Lavender Daisy'. HortScience 49:1600-1604.

Augustinova, L., J. Dolezalova, P. Matiska, Z. Wimmerova, and T. Kodetova. 2016. Testing the winter hardiness of selected chrysanthemum cultivars of multiflora type. HortScience 43:203-210

Bestfleisch, M., J. Mohring, M.V. Hanke, A. Peil, and H. Flachowsky. 2014. A diallel crossing approach aimed on selection for ripening time and yield in breeding of new strawberry (Fragaria $\times$ ananassa Duch.) cultivars. Plant Breeding 133(1):115-120.

Chen, J.Y., S.Q. Wang, X.C. Wang, and P.W. Wang. 1995. Thirty years' studies on breeding ground-cover chrysanthemum new cultivars. Acta Hort. 404:30-36. (abstr.).

Cheng, X., S.M. Chen, F.D. Chen, Y.M. Deng, W.M. Fang, F.P. Tang, Z.L. Liu, and W. Shao. 2011. Creating novel chrysanthemum germplasm via interspecific hybridization and backcrossing. Euphytica 177(1):45-53.

Cockshull, K.E. 1985. Chrysanthemum morifolium, p. 236-257. In: A.H. Halevy (ed.). CRC handbook of flowering. Vol. 2. CRC Press, Boca Raton, FL.

Deng, J.L. 1989. Introduction to grey system theory. J. Grey Syst. 1(1):1-24.

Fukai, S., T. Nagira, and M. Goi. 2000. Characteristics of $\mathrm{F}_{1}$ progenies between Chrysanthemum and some Dendrathema species. Acta Hort. 541:1-5.

Hong, Y., X.X. Bai, W. Sun, W.F. Jia, and S.L. Dai. 2012. The numerical classification of chrysanthemum flower color phenotype. Acta Hort. Sin. 39(7):1330-1340.

Huang, M.Q. and B. Wang. 2014. Evaluating green performance of building products based on gray relational analysis and analytic hierarchy process. Environ. Prog. Sustain. Energy 33(4): 1389-1395.

Hung, H.Y., C. Browne, K. Guill, N. Coles, M. Eller, A. Garcia, N. Lepak, S. Melia-Hancock, M. Oropeza-Rosas, S. Salvo, N. Upadyayula, E.S. Buckler, S. Flint-Garcia, M.D. McMullen, T.R. Rocheford, and J.B. Holland. 2012. The relationship between parental genetic or phenotypic divergence and progeny variation in the maize nested association mapping population. Heredity 108(5):490-499.

International Union for the Protection of New Varieties of Plants (UPOV). 2010. Guidelines for the conduct of tests for distinctness, uniformity and stability. Chrysanthemum (Chrysanthemum ×morifolium Ramat.). Geneva, Switzerland.

Kawamura, K., T. Kawanabe, M. Shimizu, A.J. Nagano, N. Saeki, K. Okazaki, M. Kaji, E.S. Dennis, K. Osabe, and R. Fujimoto. 2016. Genetic distance of inbred lines of chinese cabbage and its relationship to heterosis. Plant Gene 5:1-7.

Liang, X.Y., X.X. Wang, G.Q. Shu, H.Q. Wei, H. Tian, and X. Wang. 2015. A review and selection of engine waste heat recovery technologies using analytic hierarchy process and grey relational analysis. Intl. J. Energy Res. 39(4): 453-471.

Lim, J.H., M.S. Shim, S.C. Sim, K.H. Oh, and J.Y Seo. 2014. Genetic variation of flower characteristics in a population derived from a cross between the chrysanthemum cultivars 'Falcao' and 'Frill Green'. Hort. Environ. Biotechnol. 55(4):322-328.

Lim, J.H., H.K. Shin, S.K. Park, H.R. Cho, H.K. Rhee, M.S. Kim, H.Y. Joung, and B.W. Yae.
2012. A spray chrysanthemum, 'Secret Pink' with early blooming, long vase life, multifloret, single flower type, and pink petals for cut flower. Korean J. Hort. Sci. 30(1):101-105.

Luo, X.Y., X.B. Song, and S.L. Dai. 2016. Variation and probability grading of quantitative characters of traditional chrysanthemum cultivars. J. Beijing For. Univ. 38(1):101-111.

Ma, Q.H., L.S. Liang, Q. Li, and G.X. Wang. 2012. Synthetical evaluation of the fruit quality of 'Dongzao' advanced selections using analytic hierarchy process and grey relational grade analysis. Acta Hort. 940(940):213-220. (abstr.).

Ochiai, M., Y. Liao, T. Shimazu, Y. Takai, K. Suzuki, S. Yano, and H. Fukui. 2015. Varietal differences in flowering and plant growth under night-break treatment with LEDs in 12 chrysanthemum cultivars. Environ. Control Biol. 53(1): $17-22$.

Saaty, T.L. 1990. How to make a decision: The analytic hierarchy process. Eur. J. Oper. Res. 48(1):9-26.

Su, J.S., F. Zhang, X.C. Yang, Y.X. Feng, X.D. Yang, Y.Y. Wu, Z.Y. Guan, W.M. Fang, and F.D. Chen. 2017. Combining ability, heterosis, genetic distance and their intercorrelations for waterlogging tolerance traits in chrysanthemum. Euphytica 213(42).

Teixeira da Silva, J.A., H. Shinoyama, R. Aida, Y. Matsushita, S.K. Raj, and F.D. Chen. 2013. Chrysanthemum biotechnology: Quo vadis? Crit. Rev. Plant Sci. 32(1):21-52.

Wang, Q., S.L. Dai, J. He, Y.S. Ji, and S. Wang. 2012. Application of grey correlation analysis and AHP method in selection of potted chrysanthemum. Scientia Agr. Sin. 45(17):3653-3660.

Xiong, Y.Y., W.T. Xia, J. Wang, Y. Liu, and C.W. Pan. 2015. Comprehensive evaluation and screening of tulip cultivars based on their ornamental value and reuse of bulbs. J. Beijing For. Univ. 37(1):107-114.

Xu, G., Y.P. Yang, S.Y. Lu, L. Li, and X.N. Song. 2011. Comprehensive evaluation of coal-fired power plants based on grey relational analysis and analytic hierarchy process. Energy Policy 39(5):2343-2351.

Yao, J.X., H.G. Li, J. Ye, and L.L. Shi. 2016. Relationship between parental genetic distance and offspring's heterosis for early growth traits in Liriodendron: Implication for parent pair selection in cross breeding. New Forests 47(1): 163-177.

Zeng, L., E. Bechere, and D.L. Boykin. 2014. Commonality analysis and selection of parents for within-boll yield components in upland cotton. Euphytica 199(3):339-348.

Zhang, F., S.M. Chen, F.D. Chen, W.M. Fang, Y.M. Deng, Q.S. Chang, and P.S. Liu. 2011. Genetic analysis and associated SRAP markers for flowering traits of chrysanthemum (Chrysanthemum morifolium). Euphytica 177(1):15-24.

Zhang, F., S.M. Chen, J.F. Jiang, Z.Y. Guan, W.M. Fang, and F.D. Chen. 2013. Genetic mapping of quantitative trait loci underlying flowering time in chrysanthemum (Chrysanthemum morifolium). PLoS One 8(12):e83023.

Zhang, Y., X.Y. Luo, J. Zhu, C. Wang, Y. Hong, J. Lu, Q.Q. Liu, B.Q. Li, M.L. Zhu, Z.F. Wang, Y.Q. Zhang, X.B. Song, P.Y. Lv, and S.L. Dai. 2014a. A classification study for chrysanthemum (Chrysanthemum $\times$ grandiflorum Tzvelv.) cultivars based on multivariate statistical analyses. J. Syst. Evol. 52(5):612-628.

Zhang, W.X., H.L. Wei, Z.H. Jiang, F.L. Cao, and G.G. Tang. 2014b. Studies on flowering phenological characteristics of ornamental crabapple cultivar group. Acta Hort. Sin. 41 (4):713-725. 

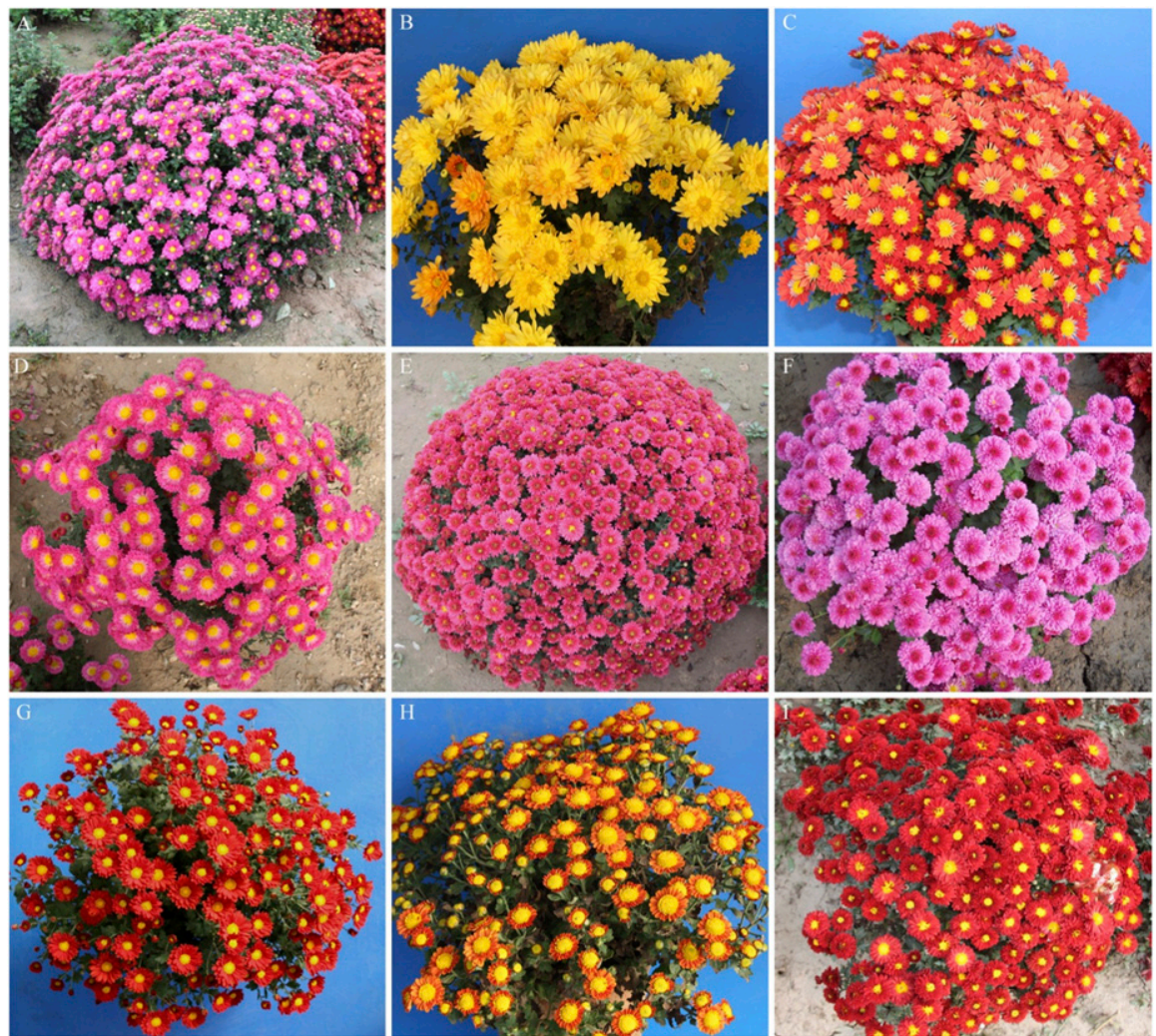

Supplemental Fig. 1. Individual performance of the selected nine crossing parents: (A) A20; (B) A7; (C) A49; (D) 317; (E) Brankiss; (F) Brancandy; (G) A42; (H) Ca*388-45; (I) A38. 
Supplemental Table 1. The source and flowering time of 505 germplasm resources.

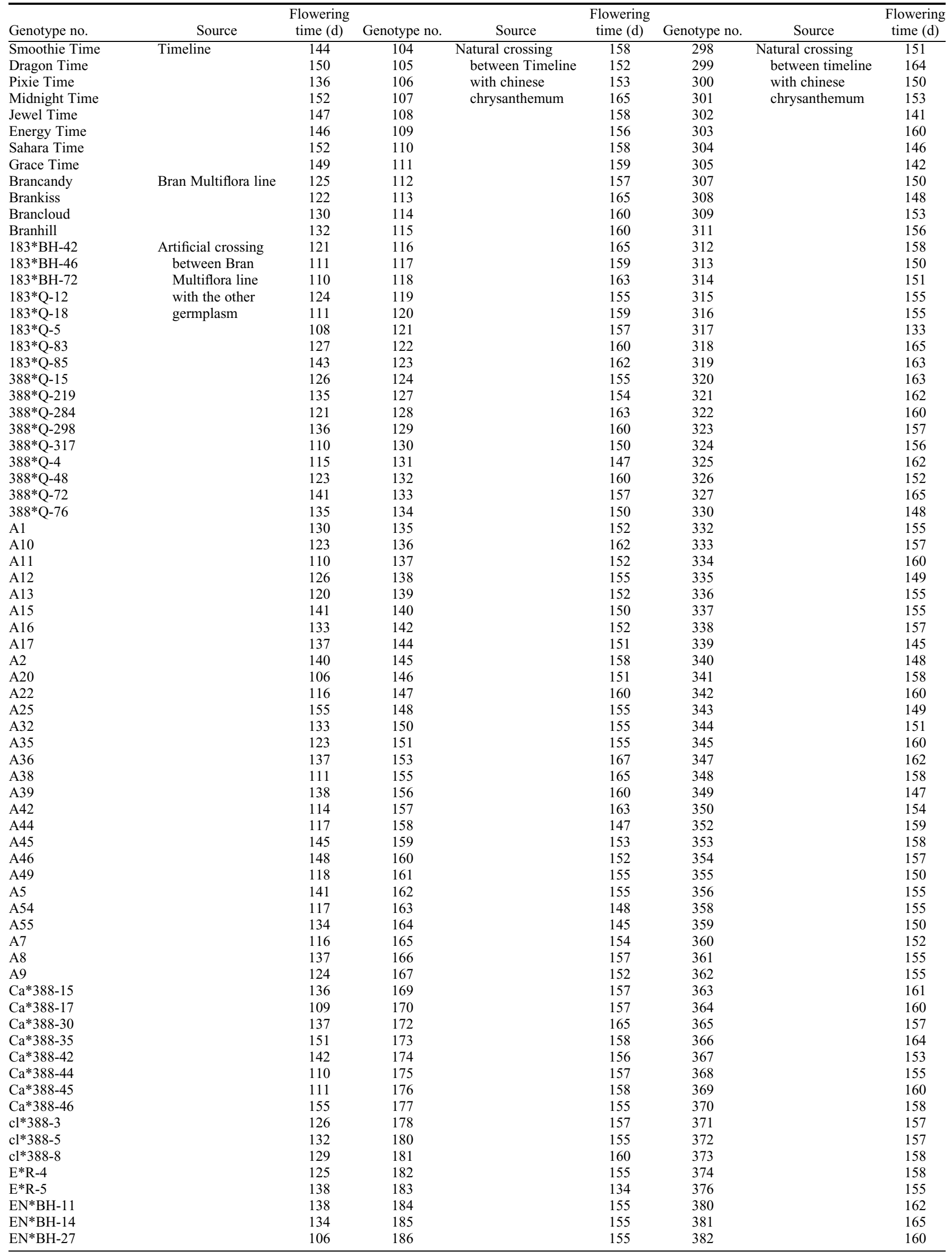

(Continued on next page) 
Supplemental Table 1. (Continued) The source and flowering time of 505 germplasm resources.

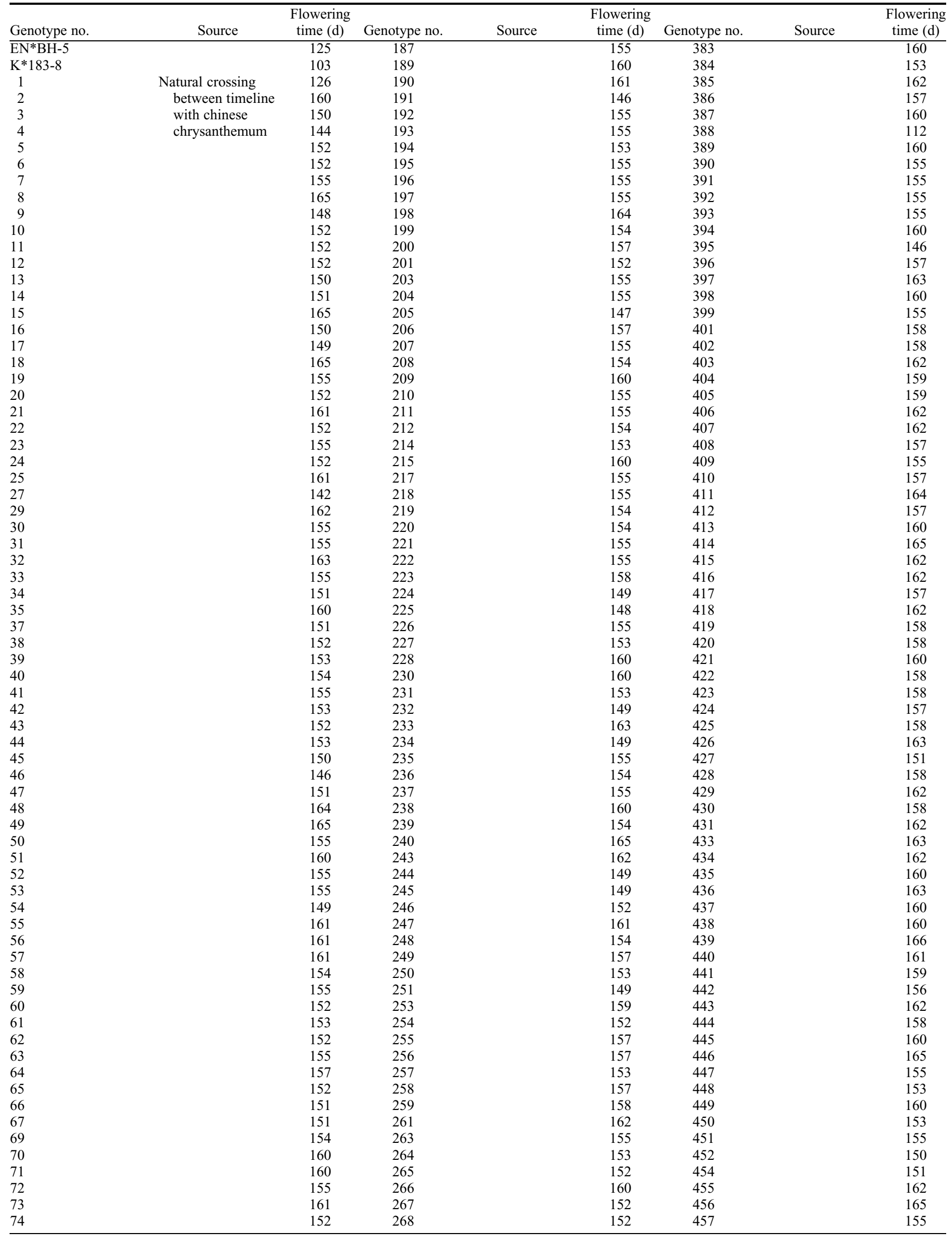

(Continued on next page) 
Supplemental Table 1. (Continued) The source and flowering time of 505 germplasm resources.

\begin{tabular}{|c|c|c|c|c|c|c|c|c|}
\hline Genotype no. & Source & $\begin{array}{c}\text { Flowering } \\
\text { time }(\mathrm{d})\end{array}$ & Genotype no. & Source & $\begin{array}{c}\text { Flowering } \\
\text { time (d) }\end{array}$ & Genotype no. & Source & $\begin{array}{c}\text { Flowering } \\
\text { time }(\mathrm{d})\end{array}$ \\
\hline 75 & & 159 & 269 & & 155 & 458 & & 153 \\
\hline 77 & & 163 & 270 & & 162 & 459 & & 162 \\
\hline 78 & & 158 & 272 & & 164 & 461 & & 155 \\
\hline 79 & & 156 & 273 & & 155 & 463 & & 166 \\
\hline 81 & & 155 & 275 & & 155 & 466 & & 155 \\
\hline 82 & & 160 & 276 & & 151 & 467 & & 151 \\
\hline 83 & & 155 & 277 & & 147 & 468 & & 153 \\
\hline 84 & & 164 & 278 & & 160 & 470 & & 158 \\
\hline 85 & & 164 & 279 & & 151 & 471 & & 162 \\
\hline 86 & & 153 & 280 & & 163 & 472 & & 155 \\
\hline 87 & & 155 & 281 & & 155 & 473 & & 155 \\
\hline 88 & & 165 & 282 & & 155 & 474 & & 158 \\
\hline 89 & & 155 & 283 & & 164 & 475 & & 137 \\
\hline 91 & & 158 & 284 & & 150 & 476 & & 160 \\
\hline 93 & & 166 & 285 & & 155 & 477 & & 159 \\
\hline 94 & & 151 & 287 & & 153 & 478 & & 163 \\
\hline 95 & & 158 & 288 & & 153 & 479 & & 158 \\
\hline 96 & & 152 & 289 & & 155 & 480 & & 164 \\
\hline 97 & & 152 & 290 & & 161 & 481 & & 160 \\
\hline 98 & & 150 & 291 & & 150 & 482 & & 158 \\
\hline 99 & & 147 & 292 & & 155 & 492 & & 140 \\
\hline 100 & & 155 & 294 & & 151 & 512 & & 130 \\
\hline 101 & & 160 & 295 & & 149 & & & \\
\hline 102 & & 144 & 297 & & 152 & & & \\
\hline
\end{tabular}

Supplemental Table 2. The daylength of key time nodes in the Beijing area in 2012-16.

\begin{tabular}{lcccc}
\hline Date & Aug. 22 & Sept. 26 & Oct. 20 & Nov. 15 \\
\hline Daylength in 2012 $\left(\mathrm{h} \cdot \mathrm{d}^{-1}\right)$ & 13.5 & 12.0 & 11.0 & 10.0 \\
Daylength in 2013 $\left(\mathrm{h} \cdot \mathrm{d}^{-1}\right)$ & 13.5 & 12.0 & 11.0 & 10.0 \\
Daylength in 2014 $\left(\mathrm{h} \cdot \mathrm{d}^{-1}\right)$ & 13.5 & 12.0 & 11.0 & 10.0 \\
Daylength in 2015 $\left(\mathrm{h} \cdot \mathrm{d}^{-1}\right)$ & 13.5 & 12.0 & 11.0 & 10.0 \\
Daylength in 2016 $\left(\mathrm{h} \cdot \mathrm{d}^{-1}\right)$ & 13.5 & 12.0 & 11.0 & 10.0 \\
\hline
\end{tabular}

Supplemental Table 3. The judgment matrix and its consistency check: A-Ci.

\begin{tabular}{lcccc}
\hline $\mathrm{A}$ & $\mathrm{C} 1$ & $\mathrm{C} 2$ & $\mathrm{C} 3$ & $\mathrm{Wt}\left(w_{i}\right)$ \\
\hline $\mathrm{C} 1$ & 1 & 6 & 7 & 0.750 \\
$\mathrm{C} 2$ & $1 / 6$ & 1 & 3 & 0.171 \\
$\mathrm{C} 3$ & $1 / 7$ & $1 / 3$ & 1 & 0.078 \\
\hline
\end{tabular}

$\lambda_{\max }=3.10, \mathrm{CI}=0.0500, \mathrm{RI}=0.58, \mathrm{CR}=0.0861$ $<0.1$. $\mathrm{CI}=$ consistency index; $\mathrm{RI}=$ random consistency index; $\mathrm{CR}=$ consistency ratio.

Supplemental Table 4. The judgment matrix and its consistency check: $\mathrm{C} 1-\mathrm{P} i$.

\begin{tabular}{lccc}
\hline C1 & P1 & P2 & Wt $\left(w_{i}\right)$ \\
\hline P1 & 1 & 7 & 0.875 \\
P2 & $1 / 7$ & 1 & 0.125 \\
\hline
\end{tabular}

$\lambda_{\max }=2.00, \mathrm{CI}=0, \mathrm{CR}=0<0.1$.

Supplemental Table 5. The judgment matrix and its consistency check: C2-P $i$.

\begin{tabular}{lcccccccl}
\hline C2 & P3 & P4 & P5 & P6 & P7 & P8 & P9 & Wt $\left(w_{i}\right)$ \\
\hline P3 & 1 & 2 & $1 / 4$ & 6 & 2 & 2 & 2 & 0.110 \\
P4 & $1 / 2$ & 1 & $1 / 4$ & 4 & $1 / 3$ & $1 / 8$ & 3 & 0.0654 \\
P5 & 4 & 4 & 1 & 5 & 4 & $1 / 2$ & 6 & 0.259 \\
P6 & $1 / 6$ & $1 / 4$ & $1 / 5$ & 1 & 1 & $1 / 5$ & 2 & 0.043 \\
P7 & $1 / 2$ & 3 & $1 / 4$ & 1 & 1 & $1 / 8$ & 1 & 0.0627 \\
P8 & $1 / 2$ & 8 & 2 & 5 & 8 & 1 & 9 & 0.421 \\
P9 & $1 / 2$ & $1 / 3$ & $1 / 6$ & $1 / 2$ & 1 & $1 / 9$ & 1 & 0.039 \\
\hline
\end{tabular}

$\overline{\lambda_{\max }=7.79, \mathrm{CI}=0.131, \mathrm{RI}=1.32, \mathrm{CR}=0.0994}$ $<0.1$.
Supplemental Table 6. The judgment matrix and its consistency check: C3-P $i$.

\begin{tabular}{lccccccl}
\hline C3 & P10 & P11 & P12 & P13 & P14 & P15 & Wt $\left(w_{i}\right)$ \\
\hline P10 & 1 & 4 & 6 & 6 & $1 / 3$ & $1 / 4$ & 0.162 \\
P11 & $1 / 4$ & 1 & 3 & 3 & $1 / 6$ & $1 / 5$ & 0.0694 \\
P12 & $1 / 6$ & $1 / 3$ & 1 & 3 & $1 / 7$ & $1 / 7$ & 0.0414 \\
P13 & $1 / 6$ & $1 / 3$ & $1 / 3$ & 1 & $1 / 9$ & $1 / 8$ & 0.0269 \\
P14 & 3 & 6 & 7 & 9 & 1 & 3 & 0.414 \\
P15 & 4 & 5 & 7 & 8 & $1 / 3$ & 1 & 0.287 \\
$\lambda_{\max }=6.52, \mathrm{CI}=0.105, \mathrm{RI}=1.24, \mathrm{CR}=0.0846$
\end{tabular}

$<0.1$. 
Supplemental Table 7. Description list of the main ornamental characters of two extremely early-flowering superior hybrids.

\begin{tabular}{|c|c|c|c|c|c|c|c|c|}
\hline Hybrid no. & $\begin{array}{l}\text { Flowering } \\
\text { time }(d)\end{array}$ & $\begin{array}{l}\text { Flowering } \\
\text { duration }(\mathrm{d})\end{array}$ & $\begin{array}{l}\text { Main color of ray } \\
\text { floret inner side }\end{array}$ & $\begin{array}{c}\text { Flower } \\
\text { head type }\end{array}$ & $\begin{array}{c}\text { Branching } \\
\text { density }\end{array}$ & $\begin{array}{l}\text { Flower } \\
\text { density }\end{array}$ & $\begin{array}{c}\text { Flower } \\
\text { head diam }(\mathrm{cm})\end{array}$ & Plant ht $(\mathrm{cm})$ \\
\hline$\overline{\mathrm{B} 8}$ & 71 & 19 & White group & Daisy-eyed double & Sparse & Sparse & 3.6 & 23.0 \\
\hline D45 & 71 & 20 & Pink group & Semidouble & Medium & Dense & 4.5 & 38.0 \\
\hline
\end{tabular}

Supplemental Table 8. Description list of the main ornamental characters of 36 early-flowering superior hybrids.

\begin{tabular}{|c|c|c|c|c|c|c|c|c|}
\hline Hybrid no. & $\begin{array}{l}\text { Flowering } \\
\text { time }(\mathrm{d})\end{array}$ & $\begin{array}{c}\text { Flowering } \\
\text { duration }(\mathrm{d})\end{array}$ & $\begin{array}{l}\text { Main color of ray } \\
\text { floret inner side }\end{array}$ & $\begin{array}{c}\text { Flower head } \\
\text { type }\end{array}$ & $\begin{array}{c}\text { Branching } \\
\text { density }\end{array}$ & Flower density & $\begin{array}{l}\text { Flower head } \\
\text { diam }(\mathrm{cm})\end{array}$ & Plant ht $(\mathrm{cm})$ \\
\hline$\overline{\mathrm{C} 22}$ & 101 & 21 & Red group & Semidouble & Medium & Medium & 3.6 & 23.0 \\
\hline $\mathrm{C} 42$ & 97 & 22 & Red group & Semidouble & Dense & Dense & 4.0 & 23.5 \\
\hline $\mathrm{C} 36$ & 97 & 21 & Red group & Semidouble & Medium & Dense & 5.1 & 20.0 \\
\hline C7 & 92 & 27 & White group & Semidouble & Medium & Dense & 4.7 & 38.5 \\
\hline D7 & 107 & 23 & Red group & Double & Medium & Medium & 4.3 & 30.0 \\
\hline D42 & 82 & 15 & Pink group & Semidouble & Medium & Sparse & 2.9 & 44.5 \\
\hline $\mathrm{C} 37$ & 95 & 22 & Red group & Semidouble & Sparse & Medium & 4.4 & 40.0 \\
\hline $\mathrm{C} 31$ & 106 & 23 & Red group & Semidouble & Dense & Dense & 3.7 & 19.8 \\
\hline D87 & 107 & 17 & Purple group & Single & Medium & Medium & 4.5 & 20.0 \\
\hline D81 & 87 & 24 & Pink group & Semidouble & Sparse & Sparse & 4.3 & 37.0 \\
\hline C52 & 105 & 26 & Red group & Semidouble & Medium & Medium & 4.2 & 43.5 \\
\hline $\mathrm{C} 50$ & 107 & 18 & Red group & Semidouble & Dense & Medium & 4.7 & 38.1 \\
\hline C55 & 105 & 28 & Red group & Semidouble & Dense & Dense & 5.3 & 16.0 \\
\hline D26 & 100 & 20 & Red group & Semidouble & Medium & Medium & 4.4 & 44.5 \\
\hline $\mathrm{C} 13$ & 102 & 21 & Red group & Semidouble & Medium & Dense & 5.8 & 49.3 \\
\hline C18 & 103 & 23 & Red group & Semidouble & Dense & Dense & 4.7 & 32.5 \\
\hline D76 & 98 & 18 & Red group & Semidouble & Medium & Dense & 3.4 & 26.0 \\
\hline D91 & 108 & 28 & Red group & Daisy-eyed double & Medium & Medium & 3.9 & 29.4 \\
\hline $\mathrm{C} 34$ & 99 & 33 & Pink group & Semidouble & Dense & Dense & 4.4 & 43.5 \\
\hline $\mathrm{C} 1$ & 105 & 21 & Red group & Semidouble & Dense & Dense & 3.7 & 20.0 \\
\hline D58 & 104 & 19 & Red group & Daisy-eyed double & Medium & Dense & 4.0 & 19.0 \\
\hline $\mathrm{C} 20$ & 108 & 19 & Red group & Semidouble & Dense & Medium & 4.3 & 47.0 \\
\hline C60 & 107 & 20 & Red group & Semidouble & Dense & Dense & 5.0 & 37.0 \\
\hline $\mathrm{C} 35$ & 107 & 20 & Red group & Daisy-eyed double & Sparse & Dense & 4.1 & 53.8 \\
\hline $\mathrm{C} 26$ & 86 & 20 & Pink group & Semidouble & Sparse & Medium & 3.8 & 40.0 \\
\hline C65 & 108 & 19 & Red group & Semidouble & Medium & Dense & 5.2 & 35.2 \\
\hline $\mathrm{C} 23$ & 106 & 20 & Red group & Semidouble & Medium & Dense & 4.0 & 45.3 \\
\hline C64 & 98 & 18 & Pink group & Semidouble & Sparse & Dense & 4.7 & 23.5 \\
\hline D63 & 104 & 21 & Red group & Semidouble & Medium & Medium & 5.3 & 45.0 \\
\hline $\mathrm{C} 17$ & 106 & 25 & Pink group & Daisy-eyed double & Dense & Medium & 5.2 & 25.9 \\
\hline C19 & 107 & 24 & Purple group & Daisy-eyed double & Sparse & Dense & 4.0 & 36.8 \\
\hline D61 & 108 & 16 & Red group & Semidouble & Medium & Medium & 4.1 & 28.3 \\
\hline $\mathrm{C} 45$ & 108 & 18 & Red group & Semidouble & Medium & Dense & 3.7 & 44.5 \\
\hline C59 & 108 & 15 & Red group & Semidouble & Medium & Dense & 3.4 & 37.5 \\
\hline C66 & 108 & 18 & Red group & Single & Sparse & Medium & 4.4 & 19.0 \\
\hline C49 & 104 & 26 & Purple group & Semidouble & Sparse & Dense & 5.1 & 50.5 \\
\hline
\end{tabular}

